\title{
Secondary Salivary Gland Malignancy in Thyroid Cancer: A United States Population Based Study
}

\author{
Eliza Sharma ${ }^{\mathrm{a}}$, Suyash Dahal ${ }^{\mathrm{b}}$, Pratibha Sharma ${ }^{\mathrm{a}}$, Abani Bhandari ${ }^{\mathrm{b}}$, \\ Vishal Gupta ${ }^{\mathrm{b}}$, Sumit Dahal ${ }^{\mathrm{c}, \mathrm{d}}$
}

\begin{abstract}
Background: There is an increased risk of second primary malignancies with thyroid cancer. However, the risk and characters of secondary salivary gland malignancy (sSGM) in patients with thyroid cancer have not been evaluated before.

Methods: We used the Surveillance Epidemiology and End Results (SEER) 18 registry to identify thyroid cancer patients from 1973 to 2014. We then calculated the risk of sSGM using standardized incidence ratio and excess risk. Separately, all cases of primary salivary gland malignancy (pSGM) diagnosed between 1973 - 2014 were extracted from the SEER 18 registry, and their characteristics compared with sSGM using independent samples $t$-test for continuous variables and Chi-square tests for categorical variables.
\end{abstract}

Results: There were a total of 68,339 cases of primary thyroid cancer. Of these, 18 patients developed sSGM with the observed to expected ratio being 3.58 ( $95 \% \mathrm{CI}: 2.12$ to $5.65 ; \mathrm{P}<0.05)$ and excess risk being 0.48 per 10,000 population. The incidence of $\mathrm{sSGM}$ remained higher between 6 months to 10 years from the time of diagnosis of thyroid carcinoma. The risk of developing sSGM was significantly higher if they were below 60 years of age (O/E: 4.51; 95\% CI: $2.33-7.88$; P $<0.05)$, were females (O/E: 4.91; 95\% CI: $2.80-7.97$; $\mathrm{P}<0.05)$, were whites (O/E: 3.04; 95\% CI: 1.62 - 5.19 ; $\mathrm{P}<0.05)$, had welldifferentiated thyroid carcinoma (O/E: 9.70; 95\% CI: 3.90 - 19.98; P $<0.05)$ or were treated with radioactive iodine (O/E: 5.26 ; $95 \% \mathrm{CI}$ : 2.72 - 9.19; $\mathrm{P}<0.05)$. While the proportion of females developing sSGM was significantly greater than those developing pSGM $(88.9 \%$ vs. $44 \%$; $\mathrm{P}<0.05$ ), there was no statistical difference between $\mathrm{pSGM}$ and sSGM in terms of the age at diagnosis, the proportion of patients diagnosed before 60 years of age, anatomic site of origin or the histological grade of tumor.

Manuscript submitted May 13, 2018, accepted May 21, 2018

${ }^{a}$ Department of Internal Medicine, Maimonides Medical Center, Brooklyn, NY, USA

bDepartment of Medicine, KIST Medical College and Teaching Hospital, Lalitpur, Nepal

'Department of Medicine, Interfaith Medical Center, Brooklyn, NY, USA

${ }^{\mathrm{d} C}$ Corresponding Author: Sumit Dahal, Department of Medicine, Interfaith

Medical Center, 1545 Atlantic Avenue, Brooklyn, NY 11213, USA.

Email:sumit.dahal@gmail.com

doi: https://doi.org/10.14740/jocmr3475w
Conclusions: Patients with thyroid cancers are at an increased risk of developing sSGM than the general population. This risk is greater if the person is below 60 years of age, female, white, with well-differentiated thyroid carcinoma or is treated with radioactive iodine.

Keywords: Salivary gland malignancy; Thyroid cancer; Second primary malignancy; SEER database

\section{Introduction}

Salivary gland tumors are heterogeneous group of uncommon tumors. They are predominantly benign. Malignant tumors of salivary gland comprise less than $1 \%$ of all cancers of head and neck [1]. Salivary gland malignancy (SGM) may occur as a primary malignancy or as a second malignancy in people with prior history of other neoplasms. Increased risk of SGM in people with benign salivary gland tumors, Hodgkin's lymphoma, medulloblastoma and basal cell carcinoma has been reported [2-5]. This may be related to the genetic predisposition to malignancy or to the associated treatments like radiation exposure. The risk and characters of such secondary salivary gland malignancy (sSGM) in patients with primary thyroid cancer has, however, not been evaluated before. In the present study, we used the National Cancer Institute's Surveillance, Epidemiology, and End Results (SEER) database of well-differentiated thyroid cancer (WTC) patients to determine the risk of sSGM compared to general population.

\section{Methods}

We identified all cases of WTC diagnosed between 1973 - 2014 from the SEER 18 registry using the following International Classification of Disease for Oncology, 3rd edition (ICDO-3) codes: 8330/3, 8331/3, 8332/3, 8335/3, 8340/3, 8341/3, $8342 / 3,8343 / 3$ and $8344 / 3$. We excluded cases diagnosed at autopsy and those lost to follow-up. Using the Warren and Gates criteria as modified by National Cancer Institute, sSGM was defined as a metachronous salivary gland malignancy developing at least 6 months after the diagnosis of WTC $[6,7]$. Patients were followed up from the time of diagnosis of WTC to the date of last known vital status, death or the last point of data collection. We used multiple primary standardized inci- 
Table 1. Secondary Salivary Gland Malignancy in Patients With Thyroid Cancer

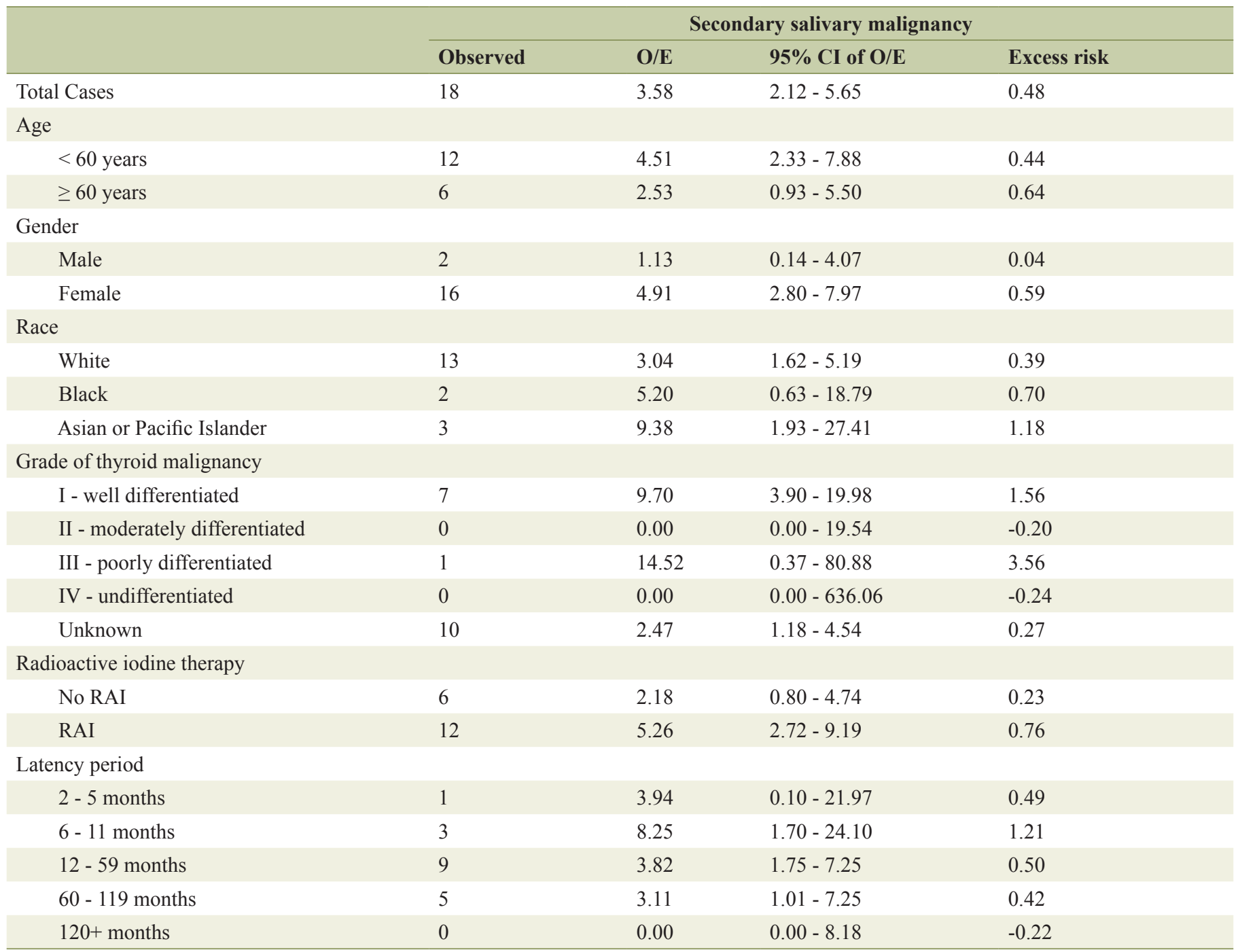

$\mathrm{Cl}$ : confidence interval; O/E: observed to expected ratio; RAI: radioactive iodine.

dence ratio session of the SEER*Stat software (version 8.3.4 - March 23, 2017) to calculate standardized incidence ratio (SIR) and excess risk (ER) of sSGM for WTC patients. Confidence intervals and P-values were calculated using Poisson exact methods for the ratio of observed to expected events. Separately, all cases of primary salivary gland malignancy (pSGM) diagnosed between 1973 - 2014 were extracted from the SEER 18 registry using the following International Statistical Classification of Diseases and Related Health Problems 10th Revision (ICD10) codes: C07.9, C08.0, C08.1, C08.8 and C08.9. The different characteristics between pSGM and sSGM were compared using independent samples $t$-test for continuous variables and Chi-square tests for categorical variables.

\section{Results}

There were a total of 68,339 patients with primary WTC in
SEER 18 registries. Of these, 18 patients developed sSGM with the observed to expected ratio $(\mathrm{O} / \mathrm{E})$ being 3.58 (95\% CI: 2.12 to $5.65 ; \mathrm{P}<0.05$ ) and excess risk (ER) being 0.48 per 10,000 population (Table 1). The median age at diagnosis for sSGM was 55 years (range 22 - 81 years) with a median latency period of 39.5 months (range 5 - 97 months) from the time of diagnosis of thyroid cancer. The incidence of sSGM remained higher between 6 months to 10 years from the time of diagnosis of thyroid cancer.

The risk of developing sSGM in those with primary thyroid carcinoma as compared to those without primary thyroid carcinoma was significantly higher among the patients below 60 years of age with an O/E of 4.51 (95\% CI: 2.33 - 7.88; $\mathrm{P}<$ 0.05 ) and ER of 0.44 per 10,000 population. Similarly, the risk was higher among females (O/E: 4.91; 95\% CI: $2.80-7.97$; P $<0.05)$ and whites (O/E: 3.04; 95\% CI: $1.62-5.19$; $\mathrm{P}<0.05)$. Furthermore, among the patients with well-differentiated thyroid carcinoma or among those treated with radioactive iodine (RAI), the incidence of sSGM was higher as compared to those 
Table 2. Characteristics of Primary and Secondary Salivary Gland Malignancy

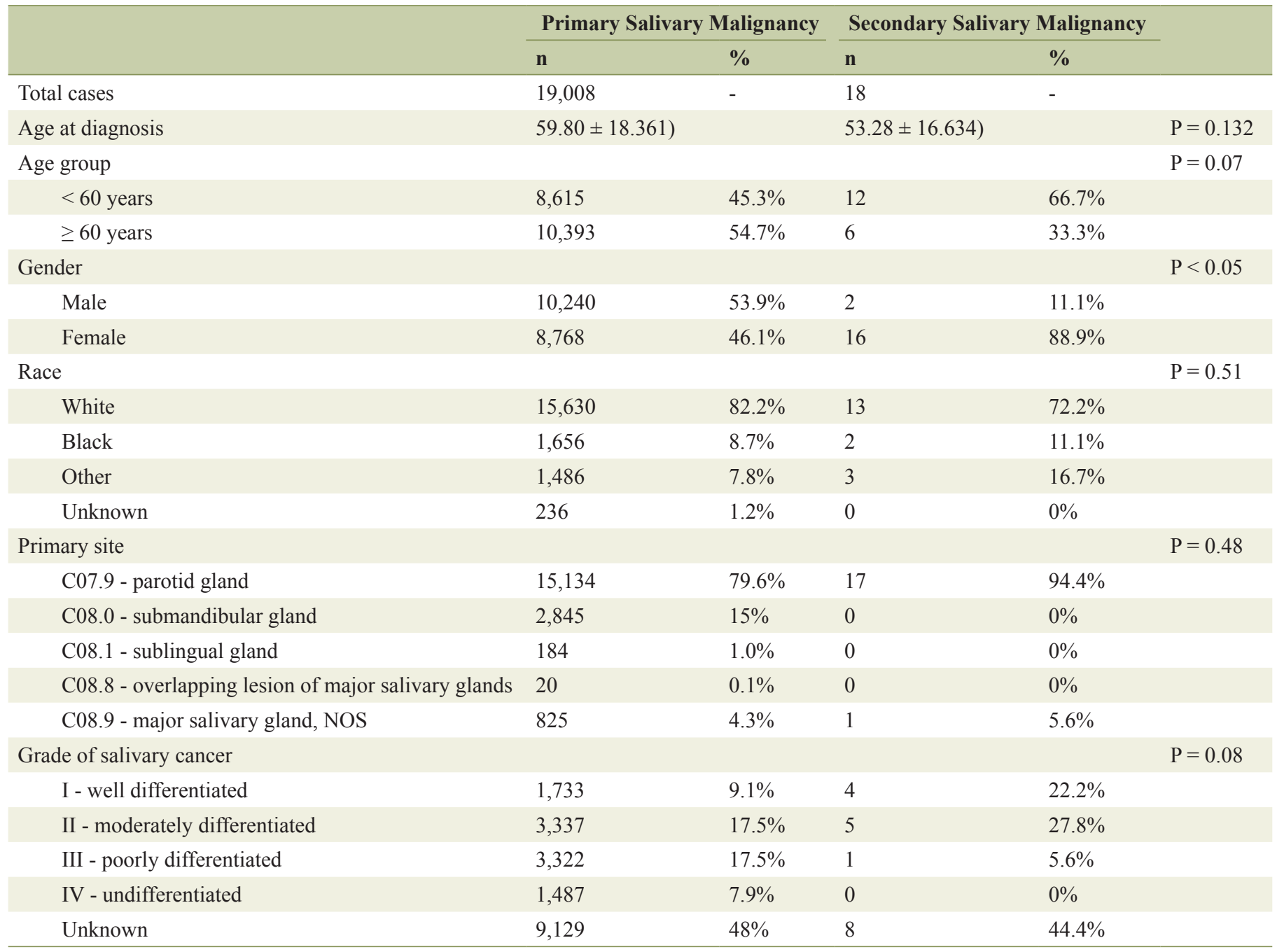

without primary thyroid carcinoma with $\mathrm{O} / \mathrm{E}$ of $9.70(95 \% \mathrm{CI}$ : 3.90 - 19.98; $\mathrm{P}<0.05)$ and 5.26 (95\% CI: 2.72 - 9.19; $\mathrm{P}<0.05)$ respectively.

There were also 19,008 cases of pSGM in the registry. There was no difference in the mean age at diagnosis $(59.80$ \pm 18.361 vs. $53.28 \pm 16.634 ; \mathrm{P}=0.132)$ or the proportion of patients below 60 years of age $(45.3 \%$ vs. $66.7 \% ; \mathrm{P}=0.07)$ in the pSGM and sSGM groups (Table 2). There were a greater proportion of females developing sSGM than pSGM $(88.9 \%$ vs. $46.1 \% ; \mathrm{P}<0.05)$. There was, however, no difference in the proportion of different races developing pSGM and sSGM. There was also no difference between the primary and secondary salivary gland malignancies (SGM) in either the proportion of the salivary gland involved or the grading of the tumor.

\section{Discussion}

Thyroid cancer is the most common endocrine malignancy with an increasing incidence over the last few decades [8, 9].
It is a malignancy of the relatively young, the median age at diagnosis being 46 years [10]. More than $90 \%$ of thyroid cancers are of well-differentiated variety consisting of papillary carcinoma and follicular carcinoma, and the 10-year survival rate is estimated to be more than $90 \%$ with appropriate treatment [11-13]. This combination of young age at diagnosis and favorable prognosis leads to an increased incidence of subsequent secondary malignancies. Several studies have estimated the incidence of second primary malignancy in thyroid cancer to be $7-8 \%[14,15]$. This has been attributed to the genetic predisposition to malignancy and associated treatments like RAI or radiation therapy [16-18].

Malignant salivary gland tumors are rare, and comprise less than $1 \%$ of all cancers of head and neck [1]. The annual incidence of malignant tumors of major salivary glands varies between slightly greater than 0.05 and less than 2 per 100,000 [19]. The incidence, however, has been increasing in recent years in United States [20]. They tend to vary considerably in their anatomic site of origin and histology. Most of the SGM are adenocarcinomas of the parotid gland [1]. This is consist- 
ent with the findings in our study, where almost four-fifths of the patients with SGM involved the parotid gland. There was also no statistically significant difference in the site of origin of pSGM and sSGM, the parotid gland being most commonly involved in both. However, malignant tumors comprise only $25 \%$ of all tumors arising in the parotid gland as compared to up to $90 \%$ of sublingual gland tumors [21]. Majority of the tumors developing in minor salivary glands tends to be malignant as well. In our study, both pSGM and sSGM were of similar histological grades. Benign parotid gland tumors may rarely turn malignant [5]. Irradiation is also a known risk factor for SGM, as is a history of prior cancers like Hodgkin's lymphoma, medulloblastoma and basal cell carcinoma [2-4, 22]. While prior studies of SGM have reported equal sex distribution with majority of patients in sixth decade of life, there were a greater proportion of males and patients above 60 years of age in our study. There was, however, no statistical difference between pSGM and sSGM in terms of the age at diagnosis or the proportion of patients diagnosed before 60 years of age.

In our study, there was a statistically significant increase in the incidence of SSGM in patients with prior thyroid cancer. This was consistent with similar findings in other studies and pooled analyses $[15,23]$. The increased risk of sSGM was seen between 6 months to 10 years from the time of diagnosis of thyroid cancer, and emphasizes the need for long-term surveillance in thyroid cancer survivors for SPM's. A greater risk of sSGM was seen with well-differentiated thyroid cancers. This may relate partly to well-differentiated variety being overwhelmingly the most common thyroid cancer and partly to its excellent prognosis enabling long enough survival for the development of sSGM. On a similar note, people who were below 60 years of age at the time of diagnosis of thyroid cancer were at greater risk of sSGM than general population. The risk of sSGM was also greater if the person was female or white. This may relate to the genetic predisposition of these groups to develop salivary gland malignancy [1]. The risk of sSGM also increased significantly in patients receiving RAI therapy for their WTC. This finding is consistent with prior studies that showed increased incidence of SPM, including that of salivary gland malignancy, with RAI-treated thyroid cancers $[15,17]$. Given the widespread use of RAI in thyroid cancer including the low grade ones, these findings warrant a more judicious approach in their use [24, 25].

Potential limitations of this study include a retrospective study design and an inability to verify the accuracy of coding. Similarly SEER program does not collect data on co-morbidities that may confound some of our findings. Despite these limitations, this study utilizes a real world data and is the largest study to specifically analyze the risk of sSGM in thyroid cancers.

In conclusion, patients with thyroid cancers are at an increased risk of developing sSGM than the general population. This risk is greater if the person is below 60 years of age, female, white, with well-differentiated thyroid carcinoma or is treated with RAI.

\section{Acknowledgments}

This study utilized the SEER 18 database. The interpretation of this data is the sole responsibility of the authors. The authors acknowledge the efforts of Surveillance Research Program, National Cancer Institute and the SEER program tumor registries in the creation of the SEER database.

\section{Conflict of Interest}

None.

\section{References}

1. Licitra L, Grandi C, Prott FJ, Schornagel JH, Bruzzi P, Molinari R. Major and minor salivary glands tumours. Crit Rev Oncol Hematol. 2003;45(2):215-225.

2. Milan T, Pukkala E, Verkasalo PK, Kaprio J, Jansen CT, Koskenvuo M, Teppo L. Subsequent primary cancers after basal-cell carcinoma: A nationwide study in Finland from 1953 to 1995. Int J Cancer. 2000;87(2):283-288.

3. Dong C, Hemminki K. Second primary neoplasms among 53159 haematolymphoproliferative malignancy patients in Sweden, 1958-1996: a search for common mechanisms. Br J Cancer. 2001;85(7):997-1005.

4. Goldstein AM, Yuen J, Tucker MA. Second cancers after medulloblastoma: population-based results from the United States and Sweden. Cancer Causes Control. 1997;8(6):865-871.

5. Spitz MR, Tilley BC, Batsakis JG, Gibeau JM, Newell GR. Risk factors for major salivary gland carcinoma. A case-comparison study. Cancer. 1984;54(9):1854-1859.

6. Warren S. Multiple primary malignant tumors. A survey of the literature and a statistical study. Am J Cancer. 1932;16:1358-1414.

7. Curtis RE, Ries LAG. Methods. New malignancies among cancer survivors: SEER cancer registries, 1973-2000. Curtis RE, Freedman DM, Ron E, Ries LAG, Hacker DG, Edwards BK, Tucker MA, Fraumeni JF (eds). National Cancer Institute. NIH Publ. No. 05-5302. Bethesda, MD. 2006:9-14.

8. Kilfoy BA, Zheng T, Holford TR, Han X, Ward MH, Sjo$\operatorname{din} \mathrm{A}$, Zhang Y, et al. International patterns and trends in thyroid cancer incidence, 1973-2002. Cancer Causes Control. 2009;20(5):525-531.

9. Davies L, Welch HG. Increasing incidence of thyroid cancer in the United States, 1973-2002. JAMA. 2006;295(18):2164-2167.

10. Hayat MJ, Howlader N, Reichman ME, Edwards BK. Cancer statistics, trends, and multiple primary cancer analyses from the Surveillance, Epidemiology, and End Results (SEER) Program. Oncologist. 2007;12(1):20-37.

11. Park SH, Suh EH, Chi JG. A histopathologic study on 1,095 surgically resected thyroid specimens. Jpn J Clin Oncol. 1988;18(4):297-302.

12. Lundgren CI, Hall P, Ekbom A, Frisell J, Zedenius J, Dickman PW. Incidence and survival of Swedish patients with differentiated thyroid cancer. Int J Cancer. 2003;106(4):569-573.

13. Gilliland FD, Hunt WC, Morris DM, Key CR. Prognostic 
factors for thyroid carcinoma. A population-based study of 15,698 cases from the Surveillance, Epidemiology and End Results (SEER) program 1973-1991. Cancer. 1997;79(3):564-573.

14. Brown AP, Chen J, Hitchcock YJ, Szabo A, Shrieve DC, Tward JD. The risk of second primary malignancies up to three decades after the treatment of differentiated thyroid cancer. J Clin Endocrinol Metab. 2008;93(2):504-515.

15. Rubino C, de Vathaire F, Dottorini ME, Hall P, Schvartz C, Couette JE, Dondon MG, et al. Second primary malignancies in thyroid cancer patients. Br J Cancer. 2003;89(9):1638-1644.

16. Teng CJ, Hu YW, Chen SC, Yeh CM, Chiang HL, Chen TJ, Liu CJ. Use of radioactive iodine for thyroid cancer and risk of second primary malignancy: a nationwide population-based study. J Natl Cancer Inst. 2016;108(2).

17. Iyer NG, Morris LG, Tuttle RM, Shaha AR, Ganly I. Rising incidence of second cancers in patients with low-risk (T1N0) thyroid cancer who receive radioactive iodine therapy. Cancer. 2011;117(19):4439-4446.

18. Sawka AM, Thabane L, Parlea L, Ibrahim-Zada I, Tsang RW, Brierley JD, Straus S, et al. Second primary malignancy risk after radioactive iodine treatment for thyroid cancer: a systematic review and meta-analysis. Thyroid. 2009;19(5):451-457.

19. Cancer incidence in five continents. Volume VIII. IARC
Sci Publ. 2002;155:1-781.

20. Carvalho AL, Nishimoto IN, Califano JA, Kowalski LP. Trends in incidence and prognosis for head and neck cancer in the United States: a site-specific analysis of the SEER database. Int J Cancer. 2005;114(5):806-816.

21. Spiro RH. Salivary neoplasms: overview of a 35year experience with 2,807 patients. Head Neck Surg. 1986;8(3):177-184.

22. Schneider AB, Lubin J, Ron E, Abrahams C, Stovall M, Goel A, Shore-Freedman E, et al. Salivary gland tumors after childhood radiation treatment for benign conditions of the head and neck: dose-response relationships. Radiat Res. 1998;149(6):625-630.

23. Subramanian S, Goldstein DP, Parlea L, Thabane L, Ezzat S, Ibrahim-Zada I, Straus S, et al. Second primary malignancy risk in thyroid cancer survivors: a systematic review and meta-analysis. Thyroid. 2007;17(12):1277-1288.

24. Jonklaas J, Sarlis NJ, Litofsky D, Ain KB, Bigos ST, Brierley JD, Cooper DS, et al. Outcomes of patients with differentiated thyroid carcinoma following initial therapy. Thyroid. 2006;16(12):1229-1242.

25. Carhill AA, Litofsky DR, Ross DS, Jonklaas J, Cooper DS, Brierley JD, Ladenson PW, et al. Long-term outcomes following therapy in differentiated thyroid carcinoma: NTCTCS registry analysis 1987-2012. J Clin Endocrinol Metab. 2015;100(9):3270-3279. 